\title{
Teacher Perceptions and Preferences for 5 School Breakfast Program Models
}

\author{
Emily B. Krueger, MS, RDN, CD; Dennis L. Eggett, PhD; Nathan Stokes, PhD
}

\begin{abstract}
Objective: Identify differences in teacher perceptions of benefits, challenges, and preferences to different School Breakfast Program (SBP) service models.

Design: A cross-sectional study design was used and an electronic survey was distributed to teachers throughout the state of Utah.

Setting: Kindergarten through 12th-grade schools throughout Utah.

Participants: A convenience sample of 369 kindergarten through 12th-grade teachers in Utah.

Variables Measured: Demographics, benefits and challenges, and teacher preference for SBP models in Utah.

Analysis: Frequencies and multiple comparison analysis tests were performed. A level of significance of $<.001$ was chosen to protect for multiple comparisons.

Results: Traditional breakfast was the most preferred model, with a mean score of 2.8; Breakfast in the Classroom was the least preferred model by teachers, with a mean of -1.3 (scale used $=-5$ to 0 to 5 ). Children not going hungry was the greatest benefit $(95.4 \% ; \mathrm{n}=352)$ to SBP and food waste was the greatest challenge $(45.8 \% ; \mathrm{n}=168)$.

Conclusions and Implications: Teachers prefer traditional SBP model over BIC and other nontraditional models. Increased awareness and education regarding benefits and challenges of SBP models may increase teacher preference for nontraditional SBP models, especially BIC.

Key Words: Breakfast in the Classroom, children, School Breakfast Program, teachers (J Nutr Educ Behav.
\end{abstract} 2018;50:788-794.)

Accepted January 11, 2018. Published online March 1, 2018.

\section{INTRODUCTION}

Obesity is an epidemic of increasing concern $^{1-3}$ that is highly correlated with negative health conditions in both adults and children. These conditions include low self-esteem, high blood pressure, gallstones, breathing difficulties, type 2 diabetes, stroke, and cancer. ${ }^{4,5}$ The school environment is an ideal location to help combat childhood obesity. This is because a majority of America's children can be reached, and school nutrition programs such as the National School Lunch
Program (NSLP) and the School Breakfast Program (SBP) have been established to promote and teach healthy practices to children at school..$^{6-8}$ Millions of students participate in these programs; almost 30 million students were served by the National School Lunch Program and more than 14 million students were served by the SBP each day in 2016. ${ }^{9,10}$

Breakfast consumption is an important component of determining a child's health status including obesity. In a study observing breakfast habits of children, Deshmukh-Taskar et al ${ }^{11}$

Department of Nutrition, Dietetics, and Food Science, Brigham Young University, Provo, UT

Conflict of Interest Disclosure: The authors have not stated any conflicts of interest.

Address for correspondence: Nathan Stokes, PhD, Department of Nutrition, Dietetics, and Food Science, Brigham Young University, S-235 Eyring Science Center, Provo, UT 84602; Phone: (801) 422-6676; Fax: (802) 422-0258; E-mail: nathan_stokes@byu.edu (C) 2018 Society for Nutrition Education and Behavior. Published by Elsevier, Inc. All rights reserved.

https://doi.org/10.1016/j.jneb.2018.01.006

indicated that children who skipped breakfast had higher body mass index, waist circumference, and prevalence of obesity than did those who ate breakfast. ${ }^{11}$ Benefits specific to SBP have been identified and include reduced absenteeism, reduced body mass index, better academic performance, better psychosocial functioning, reduced hyperactivity, and improved nutrition. . $2-14^{-14}$ Challenges to SBP include time constraints, social stigmatization, perceived lack of nutrition in breakfast meals, and increased monitoring needs of children. ${ }^{15,16}$

To take advantage of the benefits and overcome the challenges of SBP, several models of SBP service have been developed, including traditional breakfast service (served in the cafeteria before the first bell), Breakfast in the Classroom (BIC) (served to students in the classroom after the bell rings), grab-and-go breakfast (prepackaged breakfast items available to students in the cafeteria or on mobile carts in hallways), second chance breakfast (students eat breakfast during a 
morning break), and breakfast vending (breakfast items available in vending machines). ${ }^{17}$ Teachers have an important role in many of these SBP models by serving breakfast in the classroom, monitoring the students during breakfast, or encouraging them to get breakfast in the cafeteria before class. ${ }^{18,19}$ Teachers are also with students during most of the day and can serve as role models in dietary practices. $^{20,21}$ However, previous research regarding teacher perceptions of SBP is limited. Studies evaluated only 1 SBP model $\left(\mathrm{BIC}^{22}\right.$ and grab-and-go $^{23}$ or SBP in general ${ }^{11,14}$ ) and gathered perceptions of multiple stakeholders (school staff, parents, and students ${ }^{22}$ and school nutrition directors and teachers ${ }^{24}$ ) rather than focusing solely on teacher perceptions.

The purpose of this study was to identify the perceptions of kindergarten through 12th-grade teachers in Utah concerning benefits, challenges, and preferences for SBP models. The specific objectives of the study were to (1) identify teacher perceptions of benefits, challenges, and preferences for each of the 5 SBP service models and (2) identify differences in teacher preferences for each of the $5 \mathrm{SBP}$ service models based on the type of model currently being used.

\section{METHODS}

\section{Participants and Recruitment}

The sample for this study consisted of a convenience sample of kindergarten through 12-grade teachers from schools throughout the state of Utah. Utah was chosen because it has the lowest SBP participation in the nation, with only $34.8 \%$ of eligible students participating in 2014-2015. ${ }^{25}$ To reach a broad sample of the population and simplify the contact and distribution process, the Utah Education Association (UEA) helped with recruitment of participants. The UEA is an organization focused on strengthening and improving public schools and the teaching profession in the state of Utah; teachers can join if they want to be involved. ${ }^{26}$ The Utah Education Association forwarded an invitation flyer via e-mail to approximately 18,000-20,000 teachers throughout the state of Utah, inviting them to par- ticipate in the survey. It forwarded the flyer a second time 2 weeks after the initial e-mail invitation, and teachers had a total of 3 weeks to complete the survey. A total of 525 participants sent data. However, owing to missing data and incomplete surveys, only 369 were usable, for a response rate of approximately $1.85 \%$ to $2.05 \%$. The researchers obtained permission for this study from the Institutional Review Board at Brigham Young University before recruitment of participants.

\section{Instrument}

The survey instrument was created using an online software program (Qualtrics, Provo, UT; 2005), to measure teachers' perceptions of SBP in Utah. Two survey instruments previously used for SBP research were employed as a reference for survey development. ${ }^{27,28}$ Items regarding challenges and benefits of SBP and increasing SBP participation were adapted from these surveys. ${ }^{27,28}$ To ensure face and content validity of the 33 question survey, a small pilot test was conducted according to the methods described by Dillman et al. ${ }^{29}$ First, 3 school nutrition and SBP experts evaluated the instrument and provided written feedback. Regarding the survey content, experts suggested that a few items be added to some of the existing questions. Items added included suburban as an option for participants' schools, mess/bugs/pests as a concern for increasing SBP participation, and social stigma as a benefit or challenge, and the addition of an other option to some questions. They also provided comments regarding editorial corrections, the length of the survey, and clarification of questions. The survey instrument was then revised according to expert comments. The average congruency percentage among the 3 expert reviewers was calculated based on individual content questions (demographic questions were not included). The congruency percentage was $90.8 \%$, which indicated content validity of the instrument. ${ }^{30}$ A small pilot test was then conducted among 6 teachers in Utah. Teachers completed the survey as well as an evaluation form with questions regarding readability of questions, the time it took to respond, and sugges- tions for improving the questionnaire. Pilot test participants did not provide suggestions for improvement; therefore, no additional revisions were necessary.

The final survey instrument consisted of 33 questions covering several topics including teachers' perceptions of benefits and challenges of the SBP (10 questions), benefits and challenges of the 5 different SBP models (6 questions), preference for each SBP model (1 question using the scale in which -5 to $-1=$ do not prefer; $0=$ neutral; and 1 to $5=$ prefer), and basic school and participant demographics (16 questions). Participants were asked to identify benefits ( 9 items) and challenges (11 items) to SBP in general. They were then asked to use a slider scale to indicate whether they perceived 13 SBP factors as a challenge $(-5$ to -1$)$ or benefit $(1-5)$ for each of the 5 SBP models. If the slider was left in the 0 position of the scale, their perception of that item was considered neutral. This scale was chosen to simplify and shorten the survey. A modified informed consent form was included as the first page of the survey; completion of the survey indicated the participant's agreement to participate.

\section{Data Analysis}

The researchers analyzed data using Statistical Analysis Systems (version 9.4, SAS Inc., Cary, NC). Descriptive statistics, including frequencies, means, and percentages, were calculated for all survey questions. An ANOVA and Tukey-Kramer tests were performed to identify differences among teachers' preferences for each SBP model based on the model currently used at their school. To have sufficient numbers for comparisons between groups, graband-go, second chance, and breakfast vending were combined into 1 variable (other) for the ANOVA and TukeyKramer tests. Significant demographic variables were identified and then included in the model to control for possible confounding variables. To account for multiple comparison bias, the significance level of $P<.001$ was chosen.

\section{RESULTS}

The majority of participants were female $(87.5 \%)$, aged 35-64 years 
Table 1. Demographic Characteristics of Teachers and Schools $(n=369)$

$\begin{array}{lrr}\text { Characteristics } & \text { n } & \text { \% } \\ \text { Gender } & & \\ \text { Male } & 46 & 12.5 \\ \text { Female } & 321 & 87.5\end{array}$

Age, y

$\begin{array}{lrr}18-24 & 8 & 2.2 \\ 25-34 & 63 & 17.1 \\ 35-44 & 110 & 29.9 \\ 45-54 & 90 & 24.5 \\ 55-64 & 87 & 23.6 \\ 65-74 & 10 & 2.7 \\ \geq 75 & 0 & 0.0\end{array}$

\section{Ethnicity}

Caucasian/white

African American or black

$339 \quad 92.6$

Hispanic/Latino

10.3

American Indian or Alaskan

10

Asian

$4 \quad 1.1$

Native Hawaiian or Pacific Islander

$3 \quad 0.8$

Other

School Breakfast Program model used at teacher's school

Traditional breakfast

$205 \quad 55.6$

Breakfast in the classroom

$148 \quad 40.1$

Grab-and-go breakfast

$24 \quad 6.5$

Second chance breakfast

Breakfast vending

$5 \quad 1.4$

Unsure which method is used

$3 \quad 0.8$

Other

$5 \quad 1.4$

$1 \quad 0.3$

\section{Grades taught}

Kindergarten through 3

$\begin{array}{ll}147 & 40.5 \\ 84 & 23.1 \\ 92 & 25.3 \\ 40 & 11.0\end{array}$

9-12

4-5

6-8

Whether school breakfast is offered

Yes

\begin{tabular}{rr}
363 & 97.6 \\
6 & 1.6 \\
3 & 0.8 \\
\hline
\end{tabular}

Unsure

Note: Totals may not equal 369 and percentages may not equal 100 owing to missing data.

(78\%), and white/Caucasian (92.6\%), and indicated teaching grades kindergarten through 5 (63.6\%) (Table 1). The 2 most common SBP models used hungry (95.4\%), students will perform better academically (84.0\%), students will have less behavior problems (52.3\%), and teachers will not have to feed students with food they personally purchased (50.4\%) (Table 2). The challenge items that were selected most often were food waste $(45.8 \%)$, not enough time for students to eat (33.9\%), increased supervision needs provided by teachers/staff (31.2\%), and takes time away from the school day (26\%) (Table 2).

Table 3 shows that teachers identified effect on students' academic performance, effect on student attendance, and likelihood of students participating as benefits for all 5 of the SBP models. The time it takes to serve breakfast, the cleanup required, and the amount of food wasted were perceived as challenges specific to BIC. Regarding traditional school breakfast, nutrition of food options available and number of food options available were identified as benefits and the cleanup required and the amount of food wasted were perceived as challenges. Overall costs associated with this method was the only item identified by teachers as a challenge for all 5 SBP models.

Traditional breakfast was the most preferred model, and BIC the least, among teachers (Table 4). The mode (most commonly selected answer) for teachers' preference for grab-and-go breakfast, second chance breakfast, and breakfast vending were all 0 , with means close to 0 as well (Table 4). Of teachers who indicated using traditional SBP, 90.2\% had a positive preference for traditional SBP and $73.2 \%$ had a negative preference for BIC. A total of $60.1 \%$ of teachers using BIC had a positive preference for BIC; however, $64.2 \%$ had a positive preference for traditional SBP and 35.8\% had a negative perception of BIC (data not shown).

When comparing teacher preferences for the different SBP models, differences were considered significant at $P<.001$ to protect for multiple comparison bias. Traditional breakfast received the highest mean preference score for all models of SBP service except for BIC (Table 5). Teachers who indicated using traditional SBP had significantly higher mean scores of preference for traditional, grab and go, second chance, and vending models than did teachers who indicated using 
BIC, but they had a significantly lower preference for BIC than did teachers who indicated using BIC. Teachers who used BIC had a significantly higher preference for BIC than did teachers who used either traditional or other SBP models (Table 5).

\section{DISCUSSION}

The purpose of this study was to identify the perceptions of kindergarten through 12th-grade teachers in Utah concerning benefits, challenges, and preferences for SBP models. As indicated earlier, the response rate for this study was low (1.85\% to $2 \%)$; however, similar response rates were found in other studies of this sample population of teachers in Utah (Utahns Against Hunger, ${ }^{31} 1 \%$ ) and a national sample of teachers (Sneed and Patten ${ }^{32} 2 \%$ ). In terms of benefits and challenges to SBP, results from this study indicated that a majority of teachers believed the greatest benefits of SBP in general were that students would not be hungry and would perform better academically. Other studies identified similar benefits of SBPs, such as higher academic grades, better testing performance, and enhanced student concentration. ${ }^{12-14}$

When identifying benefits and challenges specific to each SBP model, the effect on students' academic performance was identified as the greatest benefit. This is unsurprising because teachers' focus is primarily on the academic growth of students. Other studies also identified improved academic performance as a benefit to SBP, including improved math scores, higher academic grades, better testing performance, improved behavior and attendance, and enhanced student concentration. ${ }^{13,14}$ The amount of cleanup required was perceived to be the greatest challenge to 4 of 5 SBP models. Previous research also identified challenges including time constraints, social stigmatization, negative perception of SBP nutrition, and increased monitoring needs of children. ${ }^{15,16}$

Teachers in this study did not seem to be aware of the costs associated with the SBP or the revenue received by SBP from the federal government. Teachers indicated that costs of the SBP were a challenge that could be the result of

Table 2. Benefits and Challenges of School Breakfast Programs in General, by Percentage of Teachers $(n=369)$

\begin{tabular}{|c|c|c|}
\hline Benefits and Challenges & $\mathbf{n}$ & $\%^{a}$ \\
\hline \multicolumn{3}{|l|}{ Benefits } \\
\hline Students will not be hungry & 352 & 95.4 \\
\hline Students will perform better academically & 310 & 84.0 \\
\hline Students will have fewer behavior problems & 193 & 52.3 \\
\hline $\begin{array}{l}\text { Teachers will not have to feed students with food they } \\
\text { personally purchased }\end{array}$ & 186 & 50.4 \\
\hline Students will have fewer absences and less tardiness & 119 & 32.2 \\
\hline There are not challenges to school breakfast programs & 86 & 23.3 \\
\hline Students will not binge at lunch & 38 & 10.3 \\
\hline The food service revenue will increase & 23 & 6.2 \\
\hline Other & 5 & 1.4 \\
\hline \multicolumn{3}{|l|}{ Challenges } \\
\hline Food waste & 168 & 45.8 \\
\hline Not enough time for students to eat & 125 & 33.9 \\
\hline Increased supervision needs provided by teachers/staff & 115 & 31.2 \\
\hline Takes time away from the school day & 96 & 26.0 \\
\hline Social stigma of those who eat breakfast at school & 83 & 22.5 \\
\hline Unsure & 53 & 14.4 \\
\hline There are no benefits to school breakfast programs & 37 & 10.0 \\
\hline Misaligned bus schedule & 33 & 8.9 \\
\hline School scheduling conflicts & 26 & 7.0 \\
\hline Students have to wait in cafeteria lines & 16 & 4.3 \\
\hline Other & 13 & 3.5 \\
\hline
\end{tabular}

aPercentage of teachers selecting as a benefit or challenge.

Note: Total responses may exceed 369 and percentages may not equal 100 owing to multiple responses.

a lack of teacher knowledge regarding costs and federal reimbursement guidelines related to SBP. Previous studies indicated that it is important for teachers to have a full understanding of the SBP to gain their support. ${ }^{23}$ Better knowledge of the costs and reimbursement guidelines as well as other aspects of SBP may help teachers promote SBP and increase participation.

This study found interesting results that differed from other studies, especially regarding BIC. Teachers indicated that their most preferred SBP model was traditional breakfast and the least preferred was BIC. These results differed from other studies among administrators and other school faculty, which concluded that perceptions of BIC were positive ${ }^{22}$ and that tradition- al breakfast had additional challenges. ${ }^{33}$ This is also interesting considering that the current initiative in Utah has been to encourage schools to switch from the traditional breakfast model to the $\mathrm{BIC}$ one. This is because of the positive academic and health outcomes associated with BIC including improved learning environments, increased attentiveness of students, and decreased tardiness and discipline issues. ${ }^{34}$

Results also indicated that the type of SBP model being used affects a teacher's perception of SBP models. In particular, teachers who were in a school using BIC had a higher preference for BIC than did teachers who used other models. Although the majority of teachers using BIC indicated a positive preference for BIC, more 
Table 3. Perceived Challenges and Benefits Specific to Each Model of School Breakfast Program Service, by Mean Score $(n=369)$

Mean Likert Score \pm SD

\begin{tabular}{|lrrrrr} 
Challenge/Benefit Items & $\begin{array}{c}\text { Traditional } \\
\text { School } \\
\text { Breakfast }\end{array}$ & $\begin{array}{c}\text { Breakfast in } \\
\text { the Classroom }\end{array}$ & $\begin{array}{c}\text { Grab-and-Go } \\
\text { Breakfast }\end{array}$ & $\begin{array}{c}\text { Second } \\
\text { Chance } \\
\text { Breakfast }\end{array}$ & $\begin{array}{c}\text { Breakfast } \\
\text { Vending }\end{array}$ \\
\hline Time it takes to serve school breakfast & $-0.3 \pm 2.24$ & $-1.9 \pm 2.56$ & $0.7 \pm 2.14$ & $-0.4 \pm 1.96$ & $0.9 \pm 2.10$ \\
\hline Cleanup required & $-1.0 \pm 2.05$ & $-1.9 \pm 2.42$ & $-0.7 \pm 2.29$ & $-1.0 \pm 1.81$ & $0.1 \pm 2.04$ \\
\hline Amount of food wasted & $-0.7 \pm 1.86$ & $-1.5 \pm 2.17$ & $-0.6 \pm 1.96$ & $-0.4 \pm 1.57$ & $0.6 \pm 1.89$ \\
\hline Nutrition of food options available & $1.1 \pm 2.16$ & $-1.0 \pm 2.34$ & $-0.7 \pm 2.02$ & $-0.2 \pm 1.72$ & $-0.9 \pm 1.89$ \\
\hline Likelihood of students participating & $0.7 \pm 2.09$ & $1.4 \pm 2.45$ & $1.1 \pm 1.85$ & $0.6 \pm 1.70$ & $0.1 \pm 1.98$ \\
\hline Flexibility in how food is served & $0.4 \pm 1.77$ & $-0.6 \pm 2.22$ & $0.9 \pm 1.93$ & $0.5 \pm 1.60$ & $0.1 \pm 1.91$ \\
\hline Amount of supervision needed & $-0.6 \pm 1.97$ & $1.1 \pm 2.45$ & $-0.1 \pm 2.11$ & $-0.6 \pm 1.90$ & $0.7 \pm 2.00$ \\
\hline Social stigma created & $-0.3 \pm 1.53$ & $0.1 \pm 2.10$ & $0.0 \pm 1.52$ & $0.1 \pm 1.24$ & $0.4 \pm 1.44$ \\
\hline Overall costs associated with this method & $-0.4 \pm 1.51$ & $-0.6 \pm 1.62$ & $-0.3 \pm 1.48$ & $-0.4 \pm 1.39$ & $-0.2 \pm 1.70$ \\
\hline Number of food options available & $0.9 \pm 2.07$ & $-1.0 \pm 2.17$ & $-0.4 \pm 1.73$ & $-0.1 \pm 1.40$ & $-0.6 \pm 1.88$ \\
\hline Effect on students' academic performance & $1.9 \pm 1.85$ & $1.4 \pm 2.09$ & $1.4 \pm 1.86$ & $1.1 \pm 1.72$ & $0.6 \pm 1.45$ \\
\hline Effect on student attendance & $1.1 \pm 1.66$ & $0.9 \pm 1.80$ & $0.7 \pm 1.44$ & $0.4 \pm 1.42$ & $0.1 \pm 1.24$ \\
\hline Ability to manage food allergies & $0.8 \pm 1.73$ & $0.1 \pm 2.01$ & $-0.4 \pm 1.66$ & $-0.2 \pm 1.43$ & $-0.2 \pm 1.67$ \\
\hline
\end{tabular}

Note: Mean scores were calculated based on responses to the following Likert scale: -5 to $-1=$ challenge; $0=$ neutral; and $1-5=$ benefit.

than one third indicated a negative preference for BIC and their mean score for preference for BIC was barely in the prefer range at 0.7 . This indicated that although the benefits of BIC are well documented, and there are currently initiatives to increase the number of schools using $\mathrm{BIC},{ }^{34}$ many teachers have a negative preference for this model.

Just over one third of participants (37\%) reported that their schools were using the BIC model; however, 35.8\% of teachers using BIC indicated that they did not prefer BIC compared with other models. In fact, BIC was the least preferred SBP model of teachers in this study (mean, -1.3 ). This was surprising because previous research showed that teachers expressed an appreciation for BIC. ${ }^{22}$ However, the previous study consisted of interviews with teachers during implementation of a BIC model and did not include teachers using other models. This could explain the more positive perception of the BIC model. Teachers also identified increased monitoring, mediating consumption, and lack of time in the school day as challenges to BIC. ${ }^{22}$ Folta et $\mathrm{al}^{22}$ also found that educational administrators thought
BIC was disruptive and that food waste was expensive. Breakfast in the Classroom is considered by many to be the ideal model for SBP. However, if use of this model is to be expanded, work must be done to educate teachers regarding its benefits and challenges to gain their support.

In terms of teacher preferences for breakfast vending, grab and go, and second chance breakfast, each had mean scores close to 0 and a mode of 0 indicating an overall neutral opinion toward these models. However, only $9 \%$ of teachers indicated that their schools implemented 1 of these 3

Table 4. Teacher Preferences of School Breakfast Models, by Mean Preference Score $(n=369)$

\begin{tabular}{lcccccc} 
Breakfast Model & Mean & Mode & SD & Do not Prefer (\%) & Neutral (\%) & Prefer (\%) \\
\hline Traditional breakfast & 2.8 & 5 & 2.53 & 7.6 & 13.3 & 79.1 \\
\hline Breakfast in the Classroom & -1.3 & -5 & 3.52 & 58.3 & 9.5 & 32.3 \\
Grab and go & 0.6 & 0 & 2.54 & 23.6 & 22.8 & 53.7 \\
\hline Second chance breakfast & 0.0 & 0 & 2.46 & 30.1 & 30.6 & 39.3 \\
Breakfast vending & -0.9 & 0 & 2.58 & 42.8 & 29.5 & 27.6 \\
\hline
\end{tabular}

Note: Means were calculated based on responses to the following scale: -5 to $-1=$ do not prefer; $0=$ neutral; and $1-5=$ prefer. 
Table 5. Comparisons of Mean Scores Between SBP Model Preferences and SBP Model Used $(n=366)$

\begin{tabular}{|c|c|c|c|c|}
\hline SBP Model & $\begin{array}{l}\text { Traditional } \\
\text { (Mean } \pm \text { SD) }\end{array}$ & $\begin{array}{l}\text { Breakfast in the Classroom } \\
(\text { Mean } \pm \text { SD) }\end{array}$ & $\begin{array}{c}\text { Other } \\
(\text { Mean } \pm \text { SD) }\end{array}$ & $P$ value \\
\hline Traditional & $1.81 \pm 0.50^{a}$ & $-0.21 \pm 0.53^{b}$ & $0.65 \pm 0.73^{a, b}$ & $<.001$ \\
\hline Breakfast in the Classroom & $-2.69 \pm 0.23^{a}$ & $0.68 \pm 0.30^{b}$ & $-2.38 \pm 0.74^{a, b}$ & $<.001$ \\
\hline Grab and go & $1.33 \pm 0.24^{a}$ & $0.12 \pm 0.27^{b}$ & $0.19 \pm 0.58^{a, b}$ & $<.001$ \\
\hline Second chance & $0.50 \pm 0.17^{a}$ & $-0.70 \pm 0.20^{b}$ & $0.28 \pm 0.57^{a, b}$ & $<.001$ \\
\hline Vending & $-0.30 \pm 0.18$ & $-1.02 \pm 0.23$ & $-1.15 \pm 0.58$ & $>.001$ \\
\hline
\end{tabular}

SBP indicates School Breakfast Program.

Notes: Grab-and-go, second chance, and vending SBP models were combined into 1 variable to have sufficient numbers for comparison across groups; items with differing superscript letters across rows have significantly different mean scores. Mean scores were calculated from the scale: -5 to $-1=$ do not prefer; $0=$ neutral; and $1-5=$ prefer.

${ }^{*} P<.001$, ANOVA and Tukey-Kramer post hoc tests.

models, could explain their apparent lack of opinion. This could also indicate that teachers' perceptions of SBP models are likely influenced by their experience and knowledge related to that model. In other words, teachers who have no experience with a particular SBP model are likely to have a neutral opinion regarding that model. That a majority of teachers had a neutral opinion to 3 of the 5 models may indicate an overall lack of experience and knowledge regarding the different SBP models among teachers.

This study had limitations. A nontypical slider scale was used for this survey, and because of an issue with the survey software, zeros had to be manually entered for neutral responses when participants did not move the slider, which had been set in the neutral position. This was an observational study and the response rate was low. In addition, the sample was not stratified or randomized and only teachers participating in the UEA were sent the link for the survey. Therefore, results cannot be generalized to the larger population. This study was performed only in the state of Utah, and therefore there may be some cultural and or regional bias.

\section{IMPLICATIONS FOR RESEARCH AND PRACTICE}

Benefits and challenges to 5 SBP models from the perspective of teachers were identified in this study and could be useful for improving SBP. Teachers and other stakeholders could be informed about the benefits of SBP, which could lead to improved perceptions of SBP as well as increased teacher support and student participation in SBP. For example, with regard to BIC, administrators and advocates of BIC need to realize the lack of knowledge and support among teachers for the BIC model and provide resources and training on the benefits of BIC as well as methods to overcome common challenges. Improved perception for BIC among teachers could lead to increased willingness to participate in and promote BIC to their students. Understanding the challenges faced by teachers when implementing these programs will help administrators develop strategies to overcome challenges and successfully implement SBP. For example, administrators could strive to develop systems to streamline clean up and reduce food waste.

The findings in this study concluded that although BIC is often seen as the most effective SBP model, there are negative perceptions regarding BIC even among those using it. Implementation of BIC models should be carefully considered by administrators and efforts should be made to ensure that teachers support these methods. Future research should also seek to better understand the reason for the negative perception of BIC among teachers, which could lead to the development of methods to improve teacher perceptions.

\section{ACKNOWLEDGMENTS}

Internal funding from Brigham Young University was used to fund this project. The authors would like to acknowledge and thank the UEA for their assistance in recruiting participants for this study. They would also like to thank all of the teachers who took the time to complete the survey.

\section{REFERENCES}

1. Ogden CL, Carroll MD, Fryar CD, Flegal KM. Prevalence of obesity among adults and youth: United States, 20112014. NCHS Data Brief. 2015;219:18.

2. Ogden CL, Carroll MD, Kit BK, Flegal KM. Prevalence of obesity and trends in body mass index among US children and adolescents, 1999-2010. JAMA. 2012; 307:483-490.

3. Centers for Disease Control and Prevention. Child obesity facts: prevalence of childhood obesity in the United States, 2011-2014. Updated November 17, 2016. https://www.cdc.gov/ obesity/data/childhood.html. Accessed November 22, 2016.

4. McMullen S. Childhood obesity: the impact on long-term risk of metabolic and CVD is not necessarily inevitable. Proc Nutr Soc. 2014;73:389-396.

5. Center for Disease Control. Childhood overweight and obesity. http:// www.cdc.gov/obesity/childhood/ index.html. Accessed December 8, 2017.

6. Briggs M, Safaii S, Beall DL. Position of the American Dietetic Association, 
Society for Nutrition Education, and American School Food Service Association. Nutrition services: an essential component of comprehensive school health programs. J Am Diet Assoc. 2003; 103:505-514.

7. Contento IR, Randell JS, Basch CE. Review and analysis of evaluation measures used in nutrition education intervention research. J Nutr Educ Behav. 2002;34:2-25.

8. Federal Register. National archives and records administration. 2012;77:181.

9. US Department of Agriculture, Food and Nutrition Services. Child nutrition tables. https://www.fns.usda.gov/pd/child -nutrition-tables. Accessed December 8 , 2017.

10. US Department of Agriculture, Food and Nutrition Service. School meals. https:// www.fns.usda.gov/school-meals/child -nutrition-programs. Accessed December 8, 2017.

11. Deshmukh-Taskar PR, Nicklas TA, O'Neil CE, Keast DR, Radcliffe JD, Cho $\mathrm{S}$. The relationship of breakfast skipping and type of breakfast consumption with nutrient intake and weight status in children and adolescents: the National Health and Nutrition Examination Survey 1999-2006. J Am Diet Assoc. 2010;110:869-878.

12. Briefel RR, Wilson A, Gleason PM. Consumption of low-nutrient, energydense foods and beverages at school, home, and other locations among school lunch participants and nonparticipants. J Am Diet Assoc. 2009;109(2 suppl):S79S90.

13. Murphy JM, Pagano ME, Nachmani J, Sperling P, Kane S, Kleinman RE. The relationship of school breakfast to psychosocial and academic functioning: cross-sectional and longitudinal observations in an inner-city school sample. Arch Pediatr Adolesc Med. 1998;152:899907.

14. Kleinman RE, Hall S, Green H, et al. Diet, breakfast, and academic performance in children. Ann Nutr Metab. 2012;46:24-30.

15. McDonnell E, Probart C, Weirich JE, Hartman T, Birkenshaw P. School breakfast programs: perceptions and bar- riers. J Child Nutr Manag. 2004;28:113.

16. Spruance LA, Harrison C, Brady P, Woolford M, LeBlanc H. Who eats school breakfast? Parent perceptions of school breakfast in a state with very low participation. J Sch Health. 2018;88:139149.

17. US Department of Agriculture, Food and Nutrition. There is more than one way to serve breakfast. https:// www.fns.usda.gov/there $\% \mathrm{E} 2 \% 80 \% 99$ s -more-one-way-serve-breakfast. Accessed December 8, 2017.

18. Neumark-Sztaine D, Story M, Harris T. Belief and attitudes about obesity among teachers and school health care providers working with adolescents. J Nutr Educ. 1999;31:3-9.

19. Koplan JP, Liverman CT, Krakk VA, Committee of Obesity in Children and Youth. Preventing Childhood Obesity: Health in the Balance. Washington, DC: National Academies Press; 2005.

20. Lytle LA, Seifert S, Greenstein J, McGovern P. How do children's eating patterns and food choices change over time? Results from a cohort study. $A m$ J Health Promot. 2000;14:222-228.

21. Kubik MY, Lytle LA, Hannah PJ, Story M, Perry CL. Food related beliefs, eating behavior, and classroom food practices of middle school teachers. $J$ Sch Health. 2002;72:339-345.

22. Folta SC, Djang HC, Halmo M, et al. School staff, parent and student perception of a breakfast in the classroom model during initial implementation. Public Health Nutr. 2015;19:1696-1706.

23. Conklin MT, Bordi PL. Middle school teachers' perceptions of a "Grab 'n Go" breakfast program. Clin Nutr. 2003;18: 192-198.

24. Lambert LG, Raidl M, Carr DH, Safaii S, Tidwell DK. School nutrition directors' and teachers' perceptions of the advantages, disadvantage, and barriers to participation in the school breakfast program. J Child Nutr Manag. 2007;31: unpaginated.

25. Food Research and Action Center. School breakfast scorecard, school year 2015-2016. Washington, DC: FRAC; 2017. http://frac.org/wp-content/ uploads/school-breakfast-scorecard-sy -2015-2016.pdf. Accessed October 3, 2017.

26. Utah Education Association. General information. http://www.myuea.org/ about_uea/general_information.aspx. Accessed December 6, 2017.

27. Askelson NM, Golembiewski EH, Ghattas A, Williams S, Delger PJ, Scheidel CA. Exploring the parents' attitudes and perceptions about school breakfast to understand why participation is low in a rural Midwest state. J Nutr Educ Behav. 2016;49:107-116.

28. Askelson NM, Golembiewski EH, Bobst A, Delger PJ, Scheidel CA. Understanding perceptions of school administrators related to school breakfast in a low school breakfast participation state. J Sch Health. 2017;87:427-434.

29. Dillman DA, Smyth JD, Christian M. Internet, Mail, and Mixed-mode Surveys: The Tailored Design Method. Hoboken, NJ: Wiley \& Sons; 2009.

30. Richards R, Brown LB, Williams DP, Eggett DL. Developing a questionnaire to evaluate college students' knowledge, attitude, behavior, self-efficacy, and environmental factors related to canned foods. J Nutr Educ Behav. 2016;49:117124.

31. Utahans Against Hunger. Too Hungry to Learn? Utah Teachers' Perspectives on Hunger in the Classroom. 2014. https:// www.uah.org/images/pdfs-doc/Too -Hungry-to-Learn1.pdf. Accessed February 5, 2018.

32. Sneed J, Patten EV. Current practices for providing school field trip meals: perspectives of school nutrition managers and teachers. J Child Nutr Manag. 2015;39: n1.

33. Sabol A, Struempler BJ, Zizza CA. Student and parent perceptions of barriers to and benefits of the school breakfast program in elementary schools in southeast Alabama. J Child Nutr Manag. 2011; 35:unpaginated.

34. Utah Breakfast Expansion Team. Starting the day right: best practices for increasing school breakfast participation in Utah schools, 2014-2015 school year. 2016. https://www.uah.org/images/ pdfs-doc/Starting_the_Day_Right _2014-2015.pdf. Accessed January 9, 2018. 